\title{
Level of anxiety among healthcare providers during COVID-19 pandemic in Saudi Arabia: cross-sectional study
}

\author{
Abbas Al Mutair ${ }^{1,2,3}$, Alya Al Mutairi ${ }^{\text {Corresp., } 4}{ }^{4}$, Yasmine Alabbasi ${ }^{5}$, Abbas Shamsan ${ }^{6}$, Sana Almahmoud ${ }^{7}$, Saad \\ Alhumaid $^{8}$, Muhammad Z. Arshad $^{9}$, Mansour Awad ${ }^{10}$, Ali A. Rabaan ${ }^{11}$ \\ ${ }^{1}$ College of Nursing, Princess Norah University, Riyadh, Saudi Arabia \\ 2 School of Nursing, University of Wollongong, Wollongong, Australia \\ 3 Research Center, Almoosa Specialist Hospital, Al-ahsa, Saudi Arabia, Al-ahsa, Saudi Arabia \\ 4 Department of Mathematics, Faculty of Science, TAIBAH UNIVERSITY, Medina, Saudi Arabia \\ 5 Maternity and Child Health Nursing Department, College of Nursing, Princess Nourah bint Abdulrahman University, Riyadh, Saudi Arabia \\ 6 Research Center, Dr. Sulaiman Al Habib Medical Group, Riyadh, Saudi Arabia \\ 7 Imam Abdurrahman Bin Faisal University, Riyadh, Saudi Arabia \\ 8 Administration of Pharmaceutical Care, Al-Ahsa Health Cluster, Ministry of Health, Riyadh, Saudi Arabia \\ 9 Department of Mathematics and Statistics, University of Agriculture, Faisalabad, Pakistan \\ 10 Commitment Administration, General Directorate of Health Affairs, Medina, Medina, Saudi Arabia \\ 11 Molecular Diagnostic Laboratory, Johns Hopkins Aramco Healthcare, Dhahran, Saudi Arabia \\ Corresponding Author: Alya Al Mutairi \\ Email address: amutairi@taibahu.edu.sa
}

Background: The burden of the spread of the COVID-19 pandemic has impacted widely on the healthcare providers physically and mentally. Many healthcare providers are exposed to psychological stressors due to their high risk of contracting the virus. Aims: This study aimed to measure the level of anxiety among healthcare providers during the COVID-19 pandemic in Saudi Arabia. Besides that, this study aimed to measure the level of anxiety based on demographic characteristics. Method: A cross-sectional survey was employed to recruit a convenience sample of healthcare providers. A pencil and paper self-administered questionnaires were used to collect data from demographic and generalized anxiety disorder GAD-7 data. However, this study received written informed consent from participants of the study. In addition, the study was approved by the Institutional Review Board at Dr. Sulaiman Al Habib Medical Group (IRB Log No. RC20.06.88-03). Results: A total of 650 participants were recruited, results of GAD-7 showed that $43.5 \%, 28.9 \%$, and $27.5 \%$ of healthcare providers in Saudi Arabia experienced mild, moderate, and severe anxiety, respectively, during the COVID-19 pandemic. Results indicated that age, health specialty, nationality, and sleeping disorders before COVID-19 were associated with anxiety levels. Conclusion: The generalized anxiety among healthcare providers in Saudi Arabia was mild. Older healthcare providers were found to have a higher level of anxiety compared to other participating healthcare providers. Several factors may contribute to a 
higher level of anxiety including age, socioeconomic status, marital status, having chronic conditions, and sleeping disorder before the COVID-19 pandemic. To further understand the level of anxiety among healthcare providers during the COVID-19 pandemic in Saudi Arabia, longitudinal and mixed-method research is needed. 


\title{
Level of Anxiety among Healthcare Providers during COVID-19 Pandemic in Saudi Arabia: Cross-Sectional Study
}

\author{
ABBAS AL MUTAIR ${ }^{1,2,3}$, ALYA AL MUTAIRI $^{4^{*}}$, YASMINE ALABBASI $^{5}$, ABBAS SHAMSAN $^{6}$, \\ SANA ALMAHMOUD ${ }^{7}$, SAAD ALHUMAID ${ }^{8}$, MUHAMMAD Z. ARSHAD ${ }^{9}$, MANSOUR AWAD $^{10}$ \\ AND ALI A. RABAAN ${ }^{11}$
}

1. Research Center Director, Almoosa Specialist Hospital, Al-ahsa, Saudi Arabia,

2. College of Nursing, Princess Norah University, Riyadh, Saudi Arabia.

3. School of Nursing, University of Wollongong, Australia; abbas4080@hotmail.com

4. Department of Mathematics, Faculty of Science, Taibah University, Medina 54321, Saudi Arabia. *Correspondence: amutairi@taibahu.edu.sa

5. Maternity and Child Health Nursing Department, College of Nursing, Princess Nourah bint Abdulrahman University, Riyadh, Saudi Arabia;yasmine2085@gmail.com

6. Research Center, Dr. Sulaiman Al Habib Medical Group, Riyadh 12214, Saudi Arabia; abbas.shamsan@drsulaimanalhabib.com

7. Imam Abdurrahman Bin Faisal University, Saudi Arabia; saalmahmoud@iau.edu.sa

8. Administration of Pharmaceutical Care, Al-Ahsa Health Cluster, Ministry of Health, Riyadh, Saudi Arabia; saalhumaid@moh.gov.sa

9. Department of Mathematics and Statistics, University of Agriculture, Faisalabad, Pakistan; profarshad@yahoo.com

10. Commitment Administration, General Directorate of Health Affairs, Medina, Saudi Arabia; Maaalmutairi2@moh.gov.sa

11. Molecular Diagnostic Laboratory, Johns Hopkins Aramco Healthcare, Dhahran, Saudi Arabia; arabaan@gmail.com

Corresponding Author:

ALYA AL MUTAIRI

Department of Mathematics, Faculty of Science, Taibah University, Medina 54321, Saudi Arabia. *Correspondence: Email address: amutairi@taibahu.edu.sa

\section{Abstract}

Background: The burden of the spread of the COVID-19 pandemic has impacted widely on the healthcare providers physically and mentally. Many healthcare providers are exposed to psychological stressors due to their high risk of contracting the virus.

Aims: This study aimed to measure the level of anxiety among healthcare providers during the COVID-19 pandemic in Saudi Arabia. Besides that, this study aimed to measure the level of anxiety based on demographic characteristics.

Method: A cross-sectional survey was employed to recruit a convenience sample of healthcare providers. A pencil and paper self-administered questionnaires were used to collect data from demographic and generalized anxiety disorder GAD-7 data. However, this study received written informed consent from participants of the study. In addition, the study was approved by 
42 the Institutional Review Board at Dr. Sulaiman Al Habib Medical Group (IRB Log No. 43 RC20.06.88-03).

44 Results: A total of 650 participants were recruited, results of GAD-7 showed that $43.5 \%, 28.9 \%$, 45 and $27.5 \%$ of healthcare providers in Saudi Arabia experienced mild, moderate, and severe 46 anxiety, respectively, during the COVID-19 pandemic. Results indicated that age, health 47 specialty, nationality, and sleeping disorders before COVID-19 were associated with anxiety 48 levels.

49 Conclusion: The generalized anxiety among healthcare providers in Saudi Arabia was mild. 50 Older healthcare providers were found to have a higher level of anxiety compared to other 51 participating healthcare providers. Several factors may contribute to a higher level of anxiety 52 including age, socioeconomic status, marital status, having chronic conditions, and sleeping 53 disorder before the COVID-19 pandemic. To further understand the level of anxiety among 54 healthcare providers during the COVID-19 pandemic in Saudi Arabia, longitudinal and mixed55 method research is needed.

56

57 Keywords: COVID-19; Anxiety; healthcare provider; mental health; health care facilities; Saudi 58 Arabia

59

60

\section{Background}

61 The coronavirus disease of 2019 (COVID-19) outbreak has spread across the world; besides, 62 there is a degree of uncertainty, concern, and worry among healthcare providers [1, 2]. These 63 64 excessive worries, intrusive thoughts, and stress may have an impact on the level of anxiety and mental health of healthcare providers $[2,3]$. In times of pandemics, such as COVID-19, healthcare providers, as the frontline force, may be prone to mental stress due to uncertainty about infectious disease and fear of contracting the virus and transmitting it to loved ones [4]. Workplace stress in healthcare industry is persistent due to several reasons including exposing to infectious diseases leading to illness or death [5]. This may produce high rates of anxiety and depression among health care providers [6]. Burnout among health care providers is also dominant due to infection and other stressors such as shortage of staff, patients load or long working hours [5]. There is growing evidence of that pandemic such as COVID-19 produces high burnout level among healthcare providers and may impact negatively on the healthcare workers mental health and emotional wellbeing $[7,8,9]$. 
75 A national survey evaluating the psychological impact of COVID-19 among the general public in 76 China during the initial stages of the COVID-19 outbreak found that $28 \%$ of respondents 77 reported moderate to severe anxiety symptoms [4]. Another study in China found that the 78 prevalence of anxiety was $44.7 \%$ (GAD $7 \geq 5$ ) among healthcare providers [10]. A survey from 79 Mental Health America (MHA) reported that $86 \%$ of healthcare providers regularly experienced 80 anxiety from June 2020 to September 2020 during the COVID-19 outbreak [2]. In Saudi Arabia, 81 the first case of COVID-19 infection was reported on March 02, 2020, amid growing concerns 82 and uncertainties among the community and healthcare providers [11]. COVID-19 cases which 83 were reported in Saudi Arabia vary in their severities from mild, moderate to severe [12, 13]. 84 Healthcare providers in Saudi Arabia are exposed to a high level of stressors due to high 85 susceptibility to getting infected which may result in a high level of burnout $[14,15,16,17,18]$. 86 Most studies have assessed the effect of COVID-19 on the anxiety and mental health of 87 healthcare providers in China [19]. However, to our knowledge, there are limited studies 88 evaluating anxiety among healthcare providers during the COVID-19 pandemic in Saudi Arabia. 89 Therefore, the purpose of this study is to measure the level of anxiety among healthcare 90 providers during the COVID-19 pandemic in Saudi Arabia. Besides that, this study aims to measure the level of anxiety based on demographic characteristics. We hypothesized that levels of anxiety among healthcare providers were associated with their demographic characteristics during the COVID-19 pandemic in Saudi Arabia.

\section{Aim of the study}

To measure the level of anxiety among healthcare providers during the COVID-19 pandemic in Saudi Arabia. Besides that, this study aimed to measure the level of anxiety based on demographic characteristics.

\section{Methods}

\section{Study design}

A cross-sectional survey study was employed to recruit a convenience sample of healthcare providers during the COVID-19 pandemic in Saudi Arabia. Prior to data collection, and ethical approval to conduct the study was sought from the Institutional Review Board at Dr. Sulaiman Al Habib Medical Group (IRB Log No. RC20.06.88-03). In addition, participants were ensured that taking part in the study is voluntary and that all gathered information will only be used for the study purposes and will be kept secured and confidential. For this cross-sectional study, no informed consent was deemed necessary and was waived by the IRB. Data were identified for 
108 the use of this publication and the study adhered to the ethical guidelines of the Declaration of 109 Helsinki and good clinical practice.

110 Both Saudi and non-Saudi healthcare providers were invited to participate in the current study.

111 Participants were included if they met the following criteria: 22 years old or above, responsible

112 for providing direct patient care in an inpatient or outpatient healthcare setting, and spent at 113 least six months in the current clinical unit. The sample size was estimated using G*Power3 and 114 based on the confidence level of $95 \%$, power of $80 \%$, and medium effect size as determined by 115 the literature review. The minimum required sample size was 356 subjects. A total of 900 116 questionnaires were distributed among healthcare providers who work in the private and public 117 healthcare sector in Riyadh city in Saudi Arabia between April 1 and 15, 2020. A total of 650 118 participants returned the completed surveys giving a response rate of $72 \%$ (Figure 1).

119

\section{Data collection instrument}

121 A pencil and paper self-administered questionnaire were used to collect data from the 122 participants. The questionnaire consisted of socio-demographic characteristics including: age, 123 gender, nationality, working area, profession, type of healthcare facility and years of working 124 experience. The questionnaire also consisted of Generalized Anxiety Disorder GAD-7. The 125 Generalized Anxiety Disorder Scale-7 CAD-7 was developed by Spitzer and colleagues [20]. It 126 is self-rated scales and consists of 7 items which have been used in multiple studies and had 127 shown acceptable reliability and good validity for assessing anxiety disorder in clinical practice 128 and research [21]. CAD-7 items are rated on a 4-point Likert Scale $(0=$ not at all, $1=$ several 129 days, 2 = over half the days and 3 = nearly every day). The scale items describe the diagnostic 130 features of the generalized anxiety disorder. The scale scores can range from 0 indicating no anxiety symptoms to 21 indicating more sever anxiety symptoms.

132

\section{Data analysis}

134 In this study standard statistical procedures were applied, data was collated into an excel spread sheet and then imported into the Statistical Package for Social Sciences (SPSS, version 25). The data was validated for accuracy and completeness before conducting the statistical analysis. A detailed descriptive and inferential statistics for all the variables constituting the socio-demographic characteristics questionnaire and Generalized Anxiety Disorder GAD-7. A descriptive analysis for socio-demographic and perceptional variables was completed in order to capture frequencies, means and standard deviations. Frequency distributions for continuous variables were examined via Shapiro-Wilk test and appropriate statistical tests were applied 
142 accordingly. An inferential statistics chi-square analysis was employed to study the association

143 between demographic profile and GAD-7. P-values of $\leq 0.05$ were accepted as the significance

144 level for all inferential statistical tests that were conducted.

145

146 Results

147 Demographic profile has been analyzed and the findings are presented in Table 1. Several 148 demographic profiles have been chosen, namely type of health care facility, age, gender, 149 nationality, the health specialty, hospital department, experiences (years), sleeping disorder 150 before COVID-19 and mental disorder. In terms of healthcare facilities, 444 (68.7\%) were 151 private facilities while only 202 (31.3\%) government. By looking at the age, about 177 (46.6\%) 152 of the respondents were at the age range 31-40 years old, followed by $123(32.4 \%)$ were 20-30 153 years old, 63 (16.6\%) were 41-50 years old and small percentage $17(4.5 \%)$ were above 50 154 years old. It was reported that more females 475 (74\%) than males $167(26 \%)$. Almost three 155 quarter of the respondents 450 (70.4\%) were non-Saudi while 189 (26\%) were Saudi. By 156 studying the health specialty, about $323(50.2 \%)$ of the respondents were nurses, followed by 157207 (32.1\%) who were others and 114 (17.7\%) physicians. Approximately $243(38.3 \%)$ of the 158 respondents worked at ICU department, followed by $206(32.4 \%)$ worked in other departments, $159134(21.1 \%)$ wards and 52 (8.2\%) worked at Emergency department. By studying the year of 160 experience, a total of 280 (44.3\%) with working experience 1-5 years, followed by $177(28 \%)$ 161 worked 6-10 years and 175 (27.7\%) worked 11 years and above. Respondents were asked 162 about sleeping disorder before COVID-19, about 532 (86.9\%) did not have sleeping disorder 163 while 80 (13.1\%) had sleeping disorder before COVID-19. Lastly, in terms of mental disorder, 164 165 about 592 (96.7\%) did not report any mental disorder, while 20 (3.3\%) had mental disorder.

167 Level of anxiety has been divided into three levels: mild, moderate and sever anxiety. The 168 findings demonstrated about 283 (43.5\%) had mild anxiety, followed by 188 (28.9\%) had 169 moderate anxiety and $179(27.5 \%)$ had severe anxiety as shown in Table 2 and Figure 2.

170

\section{The association between demographic characteristics and level of anxiety}

172 Chi-square analysis has been computed to examine the association between level of anxiety 173 and demographic profile (see Table 3). As reported, age [X2 = 12.892, df $=6$, $p<0.05$, 174 nationality [X2 $=8.321$, df $=2, p<0.05]$, health specialty [X2 $=9.543$, df $=4, p<0.05]$ and 175 sleeping disorder before COVID-19 [X2 = 12.127, $\mathrm{df}=2, \mathrm{p}<0.05]$ have significant association 
176 with anxiety level. While type of health care facilities [X2 $=2.377, \mathrm{df}=2, \mathrm{p}>0.05]$, gender [X2 =

$1773.683, \mathrm{df}=2, \mathrm{p}>0.05]$, hospital department $[\mathrm{X} 2=10.216, \mathrm{df}=6, \mathrm{p}>0.05]$, years of experience

$178[\mathrm{X} 2=7.134, \mathrm{df}=4, \mathrm{p}>0.05]$ and mental disorder $[\mathrm{X} 2=5.919, \mathrm{df}=2, \mathrm{p}>0.05]$ have no 179 significant association with level of anxiety. Descriptive analysis is shown in Table 4. In terms of 180 age, we found that respondents at the age 31-40 years (46.6 \pm 7.62 ) perceived anxiety 181 significantly higher than above 50 years old $(4.5 \pm 4.29)$. Additionally, Saudi perceived more 182 anxiety $(8.33 \pm 5.54)$ as compared to non-Saudi $(7.33 \pm 5.88)$. In terms of health specialty, 183 others healthcare providers $(8.05 \pm 6.01)$ exhibited higher anxiety level as compared to nurses 184 (7.26 \pm 5.68$)$. Also, those who had sleeping disorders before COVID-19 (8.98 \pm 5.32$)$ perceived 185 higher anxiety than those who did not have sleeping disorder (7.04 \pm 5.51$)$.

\section{Effect of demographic factors on level of anxiety}

187 The Chi-square test showed that working experience and age groups were highly associate $(p<$ 188 0.001). The results showed that older age groups were associate with longer working 189 experience. The final results of ordinal logistic regression were summarized and presented in 190 Table 5 and Table 6. In the final model, only three significant factors were remained; gender, 191 nationality, and sleeping disorder. They were found to significantly explain the odds of having 192 general anxiety disorder. Based on summary statistic, final model was significant $193[\mathrm{X} 2=19.292, \mathrm{df}=3, \mathrm{p}<0.05]$. As for goodness of fit index, both Pearson $[X 2=10.897, \mathrm{df}=11, \mathrm{p}>0.05]$ 194 and Deviance $[X 2=11.231, \mathrm{df}=11, \mathrm{p}>0.05]$ showed that the final model has good fit with the data. 195 Lastly, the assumption of proportional odds (parallel lines test) showed that the assumption was 196 met $[X 2=5.826, d f=3, p>0.05]$. Therefore, the model results can be used for interpretation. 197 Gender has effect on participants' anxiety level, the $P$ value of -0.38 indicating that male 198 participants are less likely to classify with higher level of anxiety compared to female (Table 6). 199 The results showed that that the odds of male participants to have higher anxiety level are 0.67 200 [95\% Cl, 0.475 to 0.970$]$ times than that of female respondents with significant statistic values of 201 Wald $X 2(1)=4.5, p=0.034$. Additionally, Saudi participants are more likely to develop higher 202 level of anxiety compared to non-Saudi 1.584 [95\% Cl, 1.127 to 2.226] times higher than non203 Saudi respondents, supported with statistical values of Wald $X 2(1)=7.0, p=0.008$. The results 204 showed that participants with sleeping disorder before COVID-19 are prone to classify with 205 higher level of anxiety compared to those who do not have such disorder 1.742 [95\% Cl, 1.119 206 to 2.713] times higher than those without sleeping disorder, with statistical significance value of 207 Wald $\mathrm{X} 2(1)=6.0, \mathrm{p}=0.014$. 


\section{Discussion}

210 During the novel coronavirus pandemic healthcare providers are risking their lives and continue 211 working with tremendous efforts towards their ethical and professional obligations. Not only do 212 healthcare providers be under psychological distress during the epidemic, but also 213 psychological consequences might accrue on the long-term $(5,12)$. This study measured the 214 level of anxiety based on demographic characteristics among healthcare providers during the 215 COVID-19 pandemic in Saudi Arabia. Survey results showed that $43.5 \%, 28.9 \%$, and $27.5 \%$ of 216 healthcare providers in Saudi Arabia experienced mild, moderate, and severe anxiety, 217 respectively, during the pandemic. Even though, during MERS-CoV epidemic in Saudi Arabia, 218 research show that hospital staff faced stressful times, and they felt anxious, nervous, and 219 emotionally distressed (22). Also, Unlike SARS and Ebola versus there were psychological 220 consequences among hospital staffs $(23,24)$. However, same finding were found in a recent

221

222

223

224

225

226

227

228

229

230

231

232

233

234

235

236

237

238

239

240

241 meta-analysis which showed that lower rates of anxiety and depression during COVID - 19 than the reported rates among healthcare providers during and after MERS and SARS (25). There were associations between some demographic characteristics and the level of anxiety. Age, health specialty, nationality, and sleeping disorders before COVID-19 were associated with anxiety levels, whereas other demographic characteristics, such as type of healthcare facility, gender, hospital department, years of experience, and mental disorders, did not influence anxiety levels. This study found that respondents between the ages of 31-40 years experienced significantly higher anxiety than respondents above 50 years old. A comparable study conducted in Saudi Arabia in March 2020 measured depression and anxiety among healthcare providers and found that participants between 30 and 39 years old were significantly associated with anxiety $(7.40 \pm 6.59, p<0.001)[16]$. Contrary to previous studies $[17,18,19]$ our study found that healthcare providers other than nurses showed higher anxiety levels $(8.05 \pm 6.01)$ compared to nurses $(7.26 \pm 5.68)$. A possible reason was the difference in demographic characteristics. The study sample mainly consisted of non-Saudi healthcare providers and many non-Saudi healthcare providers may live away from their loved ones. This may contribute to anxiety and depression level increase among healthcare providers, as non-Saudi mainly live alone and away from their family which may result in high level of anxiety and psychological distress [12]. Our study further measured the level of anxiety based on nationality. Findings showed that anxiety levels among Saudi healthcare providers $(8.33 \pm 5.54)$ were significantly higher than non-Saudi providers $(7.33 \pm 5.88)$. Many factors may contribute to higher anxiety levels among Saudi healthcare providers, regardless of their professional designation. These 
242 include socioeconomic status, marital status, having a chronic health condition, fear of 243 contracting the virus, living with an immunocompromised, chronically ill, or elderly person [26, $24427,28]$. A Saudi-based study measuring the overall emotional wellbeing and its predictors of the 245 Saudi population during the COVID-19 pandemic found that age, gender, marital status, and 246 socioeconomic status are majors' predictors of emotional wellbeing [29]. Similar concerns and 247 fears about transmitting the virus to their families were reported among healthcare providers 248 during the severe acute respiratory syndrome (SARS) outbreak in 2003 [29]. Cultural norms and 249 differences in living conditions among Saudi and non-Saudi healthcare providers may contribute 250 to higher anxiety levels. In terms of sleeping disorders, this study found that healthcare 251 providers who had sleeping disorders before COVID-19 exhibited higher anxiety $(8.98 \pm 5.32)$ 252 compared to those who did not have sleeping disorders $(7.04 \pm 5.51)$ [X2 $=12.127, \mathrm{df}=2, \mathrm{p}<$ 253 0.05]. This is important because a systematic review and meta-analysis found that the 254 prevalence of sleep disturbances during COVID-19 was approximately $34.8 \%$ among nurses in 255 six of the reviewed studies and $41.6 \%$ among physicians in four of the studies reviewed [30]. 256 Previous studies found that sleeping disorders among healthcare providers were associated 257 with an $83 \%$ event of adverse safety outcomes, such as motor vehicle crashes, exposure to 258 potentially infectious materials, and medical errors [31, 32]. Moreover, screening positive for 259 anxiety or depression increased the risk of adverse safety outcomes by $63 \%$ [33, 34]. Anxiety 260 among healthcare providers accompanied by sleeping disorders during the pandemic crisis may 261 interfere with physical, mental, and emotional functioning, and result in adverse occupational 262 safety outcomes. Possible limitations of this study include its cross-sectional design, as casual 263 inferences should not be made. The limitations also relate to the GAD-7 scale, as it screens for 264 an anxiety disorder and provides a probable diagnosis that must be confirmed with a physical 265 examination or blood tests to rule out thyroid dysfunction [35, 36]. Since recruitments were 266 made via questionnaire, healthcare providers who responded may be more self-aware and 267 interested in revealing their concerns. This study represented Saudi and non-Saudi healthcare 268 providers, so there may be cultural norms and differences in living conditions that might have 269 affected our findings. Future research may use a longitudinal study design to understand the 270 pattern of the levels of anxiety among healthcare providers over time during the COVID-19 271 pandemic. In addition, further research may use a mixed-method design that allows qualitative 272 and quantitative data integration, thus providing a broader, in-depth knowledge of the effect of 273 COVID-19 on anxiety levels among healthcare providers. Future studies may also compare the 274 effects of COVID-19 on anxiety levels among Saudi and non-Saudi healthcare providers. 275 


\section{Conclusion}

277 In conclusion, this Saudi-based study identified that healthcare providers' overall generalized 278 anxiety disorder during the COVID-19 pandemic was classified as mild. Results showed that the 279 31-40 age group, healthcare providers other than nurses and physicians, Saudi nationality, and 280 healthcare providers with sleeping disorders before COVID-19 were associated with anxiety 281 levels. Several factors might contribute to higher anxiety levels among Saudi healthcare 282 providers: such as marital status, socioeconomic status, having a chronic health condition, fear 283 of contracting the virus, or living with a person at high risk for severe illness. To further 284 understand the level of anxiety among healthcare providers during the COVID-19 pandemic in 285 Saudi Arabia, longitudinal and mixed-method research is needed. When these factors were 286 examined simultaneously, study found that gender, nationality, and sleeping disorder before 287 Covid-19 are the main significant factors for anxiety levels. It was found that being a Female, 288 Saudi nationality, and having sleeping disorder before Covid-19 greatly increase the odds of 289 having higher level of anxiety.

291 List of Abbreviations

292 COVID-19: Coronavirus disease 201; SARS-CoV-2: Severe acute respiratory syndrome 293 coronavirus 2; GAD: Generalized anxiety disorder; WHO: World Health Organization; IRB: 294 Institutional Review Board; HCWs: Health care works; SPSS: Statistical Package for the Social 295 Sciences; SD: Standard deviation; IQR: Interquartile range; SDS: Self-Rating Depression Scale. 296

Ethics approval and consent to participate

301 The following information was supplied relating to ethical approvals (i.e., approving body and 302 reference number): The Institutional Review Board at Dr. Sulaiman Al Habib Medical Group 303 (IRB Log No. RC20.06.88-03).

304

\section{Consent for publication}

306 Participation in the study was voluntary and participants were ensured that information gathered 307 for the study would be kept confidential and will be used for the study purposes only. 
309 Availability of data and materials

310 Not applicable

311

312 Competing interests

313 ABBAS AL MUTAIR and ABBAS SHAMSAN were employed by Dr. Sulaiman Al Habib

314 Medical Group, other authors declare no conflict of interest in preparing this article

315

316 Funding

317 Not applicable

318

319 Authors' contributions

320 ABBAS AL MUTAIR: Conceptualization, writing-original draft preparation, supervision, ethical 321 approval; ALYA AL MUTAIRI: Formal analysis, Data analysis, Interpretations; YASMINE 322 ALABBASI \& ALI RABAAN: Writing-review and editing; ABBAS SHAMSAN: Resources, 323 data curation, writing-original draft preparation; SANA ALMAHMOUD \& MANSOUR 324 AWAD: Resources, data curation, writing-review and editing; SAAD ALHUMAID: Resources, 325 data curation, writing-original draft preparation; MUHAMMAD Z. ARSHAD: Methodology, 326 Resources, editing.

327

328

329

330

\section{Acknowledgements}

The authors declare no conflict of interest in preparing this article, authors thank the referee for constructive comments.

331

332

333

334

335

336

337

338

339

\section{References}

1. World Health Organizataion. Mental health and COVID-19; 2021. Available from: https://www.euro.who.int/en/health-topics/health-emergencies/coronavirus-covid19/publications-and-technical-guidance/noncommunicable-diseases/mental-health-andcovid-19. Accessed March 14, 2021

2. Mental Health America. The mental health of healthcare workers in COVID-19; 2020. Avaiable from: https://mhanational.org/mental-health-healthcare-workers-covid19\#: :text=The $\% 20$ responses $\% 20$ collected $\% 20$ from $\% 20$ the, $75 \% 25 \% 20$ said $\% 20$ they $\% 20$ w ere\%20overwhelmed. Accessed April,1 2021. 
340

341

342

343

344

345

346

347

348

349

350

351

352

353

354

356

357

358

359

360

361

362

363

364

365

366

367

3. American Psychological Association. Anxiety; 2021. Available from: https://www.apa.org/topics/anxiety\#: :text=Anxiety\%20is\%20an\%20emotion\%20characteriz ed,certain\%20situations\%20out\%20of\%20worry. Accessed March15, 2021.

4. Wang, C., Pan, R., Wan, X., Tan, Y., Xu, L., Ho, C. S., \& Ho, R. C. (2020). Immediate psychological responses and associated factors during the initial stage of the 2019 coronavirus disease (COVID-19) epidemic among the general population in China. International journal of environmental research and public health, 17(5), 1729.

5. Al Mutair, A., Al Mutairi, A., Ambani, Z., Shamsan, A., AlMahmoud, S., \& Alhumaid, S. (2021). The impact of COVID-19 pandemic on the level of depression among health care workers: cross-sectional study. PeerJ, 9.

6. Magnavita, N., Chirico, F., Garbarino, S., Bragazzi, N. L., Santacroce, E., \& Zaffina, S. (2021). SARS/MERS/SARS-CoV-2 outbreaks and Burnout Syndrome among healthcare workers. An umbrella systematic review. International Journal of Environmental Research and Public Health, 18(8), 4361.

7. Chirico, F., \& Magnavita, N. (2020). The crucial role of occupational health surveillance for health-care workers during the COVID-19 pandemic.

8. CHIRICO, F., FERRARI, G., NUCERA, G., SZARPAK, L., CRESCENZO, P., \& ILESANMI, O. (2021). Prevalence of anxiety, depression, burnout syndrome, and mental health disorders among healthcare workers during the COVID-19 pandemic: A rapid umbrella review of systematic reviews. Journal of Health and Social Sciences, 6(2), 209-220.

9. Chirico, F., \& Nucera, G. (2020). Tribute to healthcare operators threatened by COVID-19 pandemic. J Health Soc Sci, 5(2), 165-168.

10. Zhang, Y., \& Ma, Z. F. (2020). Impact of the COVID-19 pandemic on mental health and quality of life among local residents in Liaoning Province, China: A cross-sectional study. International journal of environmental research and public health, 17(7), 2381.

11. Ministery of Health. $\mathrm{MOH}$ news. 2020; Available from: https://www.moh.gov.sa/en/Ministry/MediaCenter/News/Pages/News-2020-03-02-002.aspx. Accessed March 15, 2021. 
368

369

370

371

372

373

374

375

376

377

378

379

380

381

382

383

384

385

386

387

388

389

390

391

392

393

394

395

12. Al Mutair, A., Alhumaid, S., Alhuqbani, W. N., Zaidi, A. R. Z., Alkoraisi, S., Al-Subaie, M. F., ... \& Al-Omari, A. (2020). Clinical, epidemiological, and laboratory characteristics of mild-tomoderate COVID-19 patients in Saudi Arabia: an observational cohort study. European Journal of Medical Research, 25(1), 1-8.

13. Al-Omari, A., Alhuqbani, W. N., Zaidi, A. R. Z., Al-Subaie, M. F., AlHindi, A. M., Abogosh, A. K., ... \& Al Mutair, A. (2020). Clinical characteristics of non-intensive care unit COVID-19 patients in Saudi Arabia: a descriptive cross-sectional study. Journal of infection and public health, 13(11), 1639-1644.

14. Al Mutair, A., Al Mohaini, M., Fernandez, R., Moxham, L., Lapkin, S., \& Ham-Baloyi, W. T. (2018). Psychometric testing of the mental health inventory in an Arabian context: Cross-cultural validation study. Nursing open, 5(3), 376-383.

15. Al Mutair, A., Al Mutairi, A., Chagla, H., Alawam, K., Alsalman, K., \& Ali, A. (2020). Examining and adapting the psychometric properties of the Maslach burnout inventoryhealth services survey (MBI-HSS) among healthcare professionals. Applied Sciences, 10(5), 1890.

16. Al-Omari, A., Al Mutair, A., Shamsan, A., \& Al Mutairi, A. (2020). Predicting burnout factors among healthcare providers at private hospitals in Saudi Arabia and United Arab Emirates: A cross-sectional study. Applied Sciences, 10(1), 157.

17. Al Mutair, A., Al Obaidan, F., Al-Muhaini, M., Al Salman, K., \& Al Mosajen, S. (2017). Crosssectional study of the overall emotional functioning of health-care providers in Saudi. Saudi Critical Care Journal, 1(3), 80.

18. Fernandez, R., ten Ham-Baloyi, W., Al Mutair, A., Lapkin, S., Moxham, L., \& Tapsell, A. (2020). Similarities and differences in well-being between Australian, Saudi Arabian and South African pre-registration nursing students. Collegian, 27(4), 416-421.

19. De Kock, J. H., Latham, H. A., Leslie, S. J., Grindle, M., Munoz, S. A., Ellis, L., ... \& O'Malley, C. M. (2021). A rapid review of the impact of COVID-19 on the mental health of healthcare workers: implications for supporting psychological well-being. BMC public health, 21(1), 1-18. 
396

397

398

399

400

401

402

403

404

405

406

407

408

409

410

411

412

413

414

415

416

417

418

419

420

421

20. Spitzer, R. L., Kroenke, K., Williams, J. B., \& Löwe, B. (2006). A brief measure for assessing generalized anxiety disorder: the GAD-7. Archives of internal medicine, 166(10), 1092-1097.

21. Rutter, L. A., \& Brown, T. A. (2017). Psychometric properties of the generalized anxiety disorder scale-7 (GAD-7) in outpatients with anxiety and mood disorders. Journal of psychopathology and behavioral assessment, 39(1), 140-146.

22. Al Mutair, A., \& Ambani, Z. (2020). Narrative review of Middle East respiratory syndrome coronavirus (MERS-CoV) infection: updates and implications for practice. Journal of International Medical Research, 48(1), 0300060519858030.

23. Lin CY, Peng YC, Wu YH, Chang J, Chan CH, Yang DY. The psychological effect of severe acute respiratory syndrome on emergency department staff. Emerg Med J 2007;24:12-7.

24. Lehmann M, Bruenahl CA, Löwe B, Addo MM, Schmiedel S, Lohse AW, Schramm C. Ebola and psychological stress of health care professionals. Emerg Infect Dis. 2015;21:913-914.

25. Pappa S, Ntella V, Giannakas T, Giannakoulis VG, Papoutsi E, Katsaounou P. Prevalence of depression, anxiety, and insomnia among healthcare workers during the COVID-19 pandemic: A systematic review and meta-analysis. Brain, behavior, and immunity. 2020 May 8.

26. AlAteeq, D. A., Aljhani, S., Althiyabi, I., \& Majzoub, S. (2020). Mental health among healthcare providers during coronavirus disease (COVID-19) outbreak in Saudi Arabia. Journal of Infection and Public Health, 13(10), 1432-1437.

27. Lai, J., Ma, S., Wang, Y., Cai, Z., Hu, J., Wei, N., ... \& Hu, S. (2020). Factors associated with mental health outcomes among health care workers exposed to coronavirus disease 2019. JAMA network open, 3(3), e203976-e203976.

28. Alenazi, T. H., BinDhim, N. F., Alenazi, M. H., Tamim, H., Almagrabi, R. S., Aljohani, S. M., ... \& Alqahtani, S. A. (2020). Prevalence and predictors of anxiety among healthcare workers in Saudi Arabia during the COVID-19 pandemic. Journal of infection and public health, 13(11), 1645-1651. 
422

423

424

425

426

427

428

429

430

431

432

433

434

435

436

437

438

439

440

441

442

443

444

445

446

447

29. Al Mutair, A., Alhajji, M., \& Shamsan, A. (2021). Emotional Wellbeing in Saudi Arabia During the COVID-19 Pandemic: A National Survey. Risk Management and Healthcare Policy, 14, 1065.

30. Maunder, R., Hunter, J., Vincent, L., Bennett, J., Peladeau, N., Leszcz, M., ... \& Mazzulli, T. (2003). The immediate psychological and occupational impact of the 2003 SARS outbreak in a teaching hospital. Cmaj, 168(10), 1245-1251.

31. Salari, N., Hosseinian-Far, A., Jalali, R., Vaisi-Raygani, A., Rasoulpoor, S., Mohammadi, M., ... \& Khaledi-Paveh, B. (2020). Prevalence of stress, anxiety, depression among the general population during the COVID-19 pandemic: a systematic review and metaanalysis. Globalization and health, 16(1), 1-11.

32. Weaver, M. D., Vetter, C., Rajaratnam, S. M., O’Brien, C. S., Qadri, S., Benca, R. M., ... \& Barger, L. K. (2018). Sleep disorders, depression and anxiety are associated with adverse safety outcomes in healthcare workers: A prospective cohort study. Journal of sleep research, 27(6), e12722.

33. Al Mutair, A., Shamsan, A., AlFaqiri, A., \& Al-Omari, A. (2019). Intensive Care Unit Patients' Perception of Sleep Quality and Factors of Sleep Disruption: Cross-sectional Study. Dr. Sulaiman Al Habib Medical Journal, 1(1), 30-35.

34. Bové, K. B., Watt, T., Vogel, A., Hegedüs, L., Bjoerner, J. B., Groenvold, M., ... \& FeldtRasmussen, U. (2014). Anxiety and depression are more prevalent in patients with Graves' disease than in patients with nodular goitre. European thyroid journal, 3(3), 173-178.

35. Al Mutair, A., Shamsan, A., Salih, S., \& Al-Omari, A. (2020). Sleep Deprivation Etiologies Among Patients in the Intensive Care Unit: Literature Review. Dimensions of Critical Care Nursing, 39(4), 203-210.

36. Brandt, F., Thvilum, M., Almind, D., Christensen, K., Green, A., Hegedüs, L., \& Brix, T. H. (2014). Hyperthyroidism and psychiatric morbidity: evidence from a Danish nationwide register study. Eur J Endocrinol, 170(2), 341-8. 


\section{Table 1 (on next page)}

Table 1

Demographic characteristics of the respondents 
Table 1. Demographic profile of the respondents

\begin{tabular}{|c|c|c|c|c|c|}
\hline \multirow[b]{2}{*}{ Demography Profile } & \multicolumn{3}{|c|}{ General Anxiety Disorder (GAD-7) } & \multirow[b]{2}{*}{$\mathrm{n}$} & \multirow[b]{2}{*}{$\%$} \\
\hline & Mild & Moderate & Severe & & \\
\hline \multicolumn{6}{|l|}{ Type of Facility } \\
\hline Government & $86(42.6 \%)$ & $66(32.7 \%)$ & $50(24.8 \%)$ & 202 & $31.3 \%$ \\
\hline Private & $194(43.7 \%)$ & $121(27.3 \%)$ & $129(29.1 \%)$ & 444 & $68.7 \%$ \\
\hline \multicolumn{6}{|l|}{ Age } \\
\hline 20-30 Years Old & $70(56.9 \%)$ & $32(26 \%)$ & $21(17.1 \%)$ & 123 & $32.4 \%$ \\
\hline 31-40 Years Old & $73(41.2 \%)$ & $56(31.6 \%)$ & $48(27.1 \%)$ & 177 & $46.6 \%$ \\
\hline 41-50 Years Old & $34(54 \%)$ & $14(22.2 \%)$ & $15(23.8 \%)$ & 63 & $16.6 \%$ \\
\hline$>50$ Years Old & $12(70.6 \%)$ & $4(23.5 \%)$ & $1(5.9 \%)$ & 17 & $4.5 \%$ \\
\hline \multicolumn{6}{|l|}{ Gender } \\
\hline Male & $78(46.7 \%)$ & $52(31.1 \%)$ & $37(22.2 \%)$ & 167 & $26.0 \%$ \\
\hline Female & $199(41.9 \%)$ & $134(28.2 \%)$ & $142(29.9 \%)$ & 475 & $74.0 \%$ \\
\hline \multicolumn{6}{|l|}{ Nationality } \\
\hline Saudi & $66(34.9 \%)$ & $67(35.4 \%)$ & $56(29.6 \%)$ & 189 & $29.6 \%$ \\
\hline Non Saudi & $210(46.7 \%)$ & $119(26.4 \%)$ & $121(26.9 \%)$ & 450 & $70.4 \%$ \\
\hline \multicolumn{6}{|l|}{ Profession } \\
\hline Physician & $45(39.5 \%)$ & $37(32.5 \%)$ & $32(28.1 \%)$ & 114 & $17.7 \%$ \\
\hline Nurse & $159(49.2 \%)$ & $81(25.1 \%)$ & $83(25.7 \%)$ & 323 & $50.2 \%$ \\
\hline Others & $76(36.7 \%)$ & $70(33.8 \%)$ & $61(29.5 \%)$ & 207 & $32.1 \%$ \\
\hline \multicolumn{6}{|l|}{ Work Area } \\
\hline ER & $18(34.6 \%)$ & $21(40.4 \%)$ & $13(25 \%)$ & 52 & $8.2 \%$ \\
\hline Ward & $71(53 \%)$ & $28(20.9 \%)$ & $35(26.1 \%)$ & 134 & $21.1 \%$ \\
\hline ICU & $100(41.2 \%)$ & $72(29.6 \%)$ & $71(29.2 \%)$ & 243 & $38.3 \%$ \\
\hline Others & $86(41.7 \%)$ & $63(30.6 \%)$ & $57(27.7 \%)$ & 206 & $32.4 \%$ \\
\hline \multicolumn{6}{|l|}{ Years of Experience } \\
\hline 1-5Years & $126(45 \%)$ & $85(30.4 \%)$ & $69(24.6 \%)$ & 280 & $44.3 \%$ \\
\hline 6-10Years & $64(36.2 \%)$ & $54(30.5 \%)$ & $59(33.3 \%)$ & 177 & $28.0 \%$ \\
\hline 11 Years and Above & $84(48 \%)$ & $46(26.3 \%)$ & $45(25.7 \%)$ & 175 & $27.7 \%$ \\
\hline \multicolumn{6}{|l|}{ Sleeping Disorder* } \\
\hline Yes & $21(26.3 \%)$ & $32(40 \%)$ & $27(33.8 \%)$ & 80 & $13.1 \%$ \\
\hline No & $250(47 \%)$ & $153(28.8 \%)$ & $129(24.2 \%)$ & 532 & $86.9 \%$ \\
\hline \multicolumn{6}{|l|}{ Mental Disorder* } \\
\hline Yes & $4(20 \%)$ & $7(35 \%)$ & $9(45 \%)$ & 20 & $3.3 \%$ \\
\hline No & $268(45.3 \%)$ & $175(29.6 \%)$ & $149(25.2 \%)$ & 592 & $96.7 \%$ \\
\hline
\end{tabular}

*Before Covid-19 incident 
Table 2 (on next page)

Table 2

Level of anxiety 
1

Table 2. Level of anxiety

\begin{tabular}{lcc}
\hline Level of anxiety & Frequency & Percent \\
\hline Mild & 283 & 43.5 \\
Moderate & 188 & 28.9 \\
Severe & 179 & 27.5 \\
Total & 650 & 100.0 \\
\hline
\end{tabular}

2 


\section{Table 3(on next page)}

Table 3

The association between demographic characteristics and level of anxiety 
1

\begin{tabular}{|c|c|c|c|c|c|c|c|c|c|}
\hline \multirow{2}{*}{ Variables } & \multicolumn{2}{|c|}{ Mild } & \multicolumn{2}{|c|}{ Moderate } & \multicolumn{2}{|c|}{ Severe } & \multirow{2}{*}{ Value } & \multirow{2}{*}{$d f$} & \multirow{2}{*}{ sig. } \\
\hline & $n$ & $\%$ & $N$ & $\%$ & $N$ & $\%$ & & & \\
\hline $\begin{array}{l}\text { Type of health care facilities } \\
\text { Government } \\
\text { Private }\end{array}$ & $\begin{array}{c}86 \\
194\end{array}$ & $\begin{array}{l}42.6 \\
43.7\end{array}$ & $\begin{array}{c}66 \\
121\end{array}$ & $\begin{array}{l}32.7 \\
27.3\end{array}$ & $\begin{array}{c}50 \\
129\end{array}$ & $\begin{array}{l}24.8 \\
29.1\end{array}$ & $2.377^{a}$ & 2 & 0.305 \\
\hline $\begin{array}{l}\text { Age } \\
20-30 \\
31-40 \\
41-50 \\
\text { Above } 50 \text { years } \\
\end{array}$ & $\begin{array}{l}70 \\
73 \\
34 \\
12 \\
\end{array}$ & $\begin{array}{c}56.9 \\
41.2 \\
53.97 \\
70.6 \\
\end{array}$ & $\begin{array}{c}32 \\
56 \\
14 \\
4 \\
\end{array}$ & $\begin{array}{l}26.0 \\
31.6 \\
22.2 \\
23.5\end{array}$ & $\begin{array}{c}21 \\
48 \\
15 \\
1 \\
\end{array}$ & $\begin{array}{c}17.1 \\
27.1 \\
23.8 \\
5.9 \\
\end{array}$ & $12.892^{a}$ & 6 & 0.045 \\
\hline $\begin{array}{l}\text { Gender } \\
\text { Male } \\
\text { Female } \\
\end{array}$ & $\begin{array}{c}78 \\
199 \\
\end{array}$ & $\begin{array}{l}46.7 \\
41.9 \\
\end{array}$ & $\begin{array}{c}52 \\
134 \\
\end{array}$ & $\begin{array}{l}31.1 \\
28.2 \\
\end{array}$ & $\begin{array}{c}37 \\
142 \\
\end{array}$ & $\begin{array}{l}22.2 \\
29.9 \\
\end{array}$ & $3.683^{\mathrm{a}}$ & 2 & 0.159 \\
\hline $\begin{array}{l}\text { Nationality } \\
\text { Saudi } \\
\text { Non-Saudi } \\
\end{array}$ & $\begin{array}{c}66 \\
210 \\
\end{array}$ & $\begin{array}{l}34.9 \\
46.7 \\
\end{array}$ & $\begin{array}{c}67 \\
119 \\
\end{array}$ & $\begin{array}{l}35.4 \\
26.4 \\
\end{array}$ & $\begin{array}{c}56 \\
121 \\
\end{array}$ & $\begin{array}{l}29.6 \\
26.9 \\
\end{array}$ & $8.321^{\mathrm{a}}$ & 2 & 0.016 \\
\hline $\begin{array}{l}\text { Health specialty } \\
\text { Physicians } \\
\text { Nurses } \\
\text { Others }\end{array}$ & $\begin{array}{c}45 \\
159 \\
76\end{array}$ & $\begin{array}{l}39.5 \\
49.2 \\
36.7 \\
\end{array}$ & $\begin{array}{l}37 \\
81 \\
70\end{array}$ & $\begin{array}{l}32.5 \\
25.1 \\
33.8 \\
\end{array}$ & $\begin{array}{l}32 \\
83 \\
61\end{array}$ & $\begin{array}{l}28.1 \\
25.7 \\
29.5\end{array}$ & $9.543^{a}$ & 4 & 0.049 \\
\hline $\begin{array}{l}\text { Hospital Department } \\
\text { ER Department } \\
\text { Ward } \\
\text { ICU Department } \\
\text { Others }\end{array}$ & $\begin{array}{c}18 \\
71 \\
100 \\
86\end{array}$ & $\begin{array}{l}34.6 \\
53.0 \\
41.2 \\
41.7\end{array}$ & $\begin{array}{l}21 \\
28 \\
72 \\
63\end{array}$ & $\begin{array}{l}40.4 \\
20.9 \\
29.6 \\
30.6\end{array}$ & $\begin{array}{l}13 \\
35 \\
71 \\
57\end{array}$ & $\begin{array}{l}25.0 \\
26.1 \\
29.2 \\
27.7\end{array}$ & $10.216^{\mathrm{a}}$ & 6 & 0.116 \\
\hline $\begin{array}{l}\text { Years of experience } \\
1-5 \text { Years } \\
6-10 \text { Years } \\
11 \text { Years and Above }\end{array}$ & $\begin{array}{c}126 \\
64 \\
84 \\
\end{array}$ & $\begin{array}{l}45.0 \\
36.2 \\
48.0 \\
\end{array}$ & $\begin{array}{l}85 \\
54 \\
46 \\
\end{array}$ & $\begin{array}{l}30.4 \\
30.5 \\
26.3 \\
\end{array}$ & $\begin{array}{l}69 \\
59 \\
45 \\
\end{array}$ & $\begin{array}{l}24.6 \\
33.3 \\
25.7 \\
\end{array}$ & $7.134^{\mathrm{a}}$ & 4 & 0.129 \\
\hline $\begin{array}{l}\text { Sleeping disorder before } \\
\text { Covid-19 } \\
\text { Yes } \\
\text { No }\end{array}$ & $\begin{array}{c}21 \\
250 \\
\end{array}$ & $\begin{array}{l}26.3 \\
47.0\end{array}$ & $\begin{array}{c}32 \\
153 \\
\end{array}$ & $\begin{array}{l}40.0 \\
28.8 \\
\end{array}$ & $\begin{array}{c}27 \\
129 \\
\end{array}$ & $\begin{array}{l}33.8 \\
24.2 \\
\end{array}$ & $12.127^{a}$ & 2 & 0.002 \\
\hline $\begin{array}{l}\text { Mental Disorder } \\
\text { Yes } \\
\text { No }\end{array}$ & $\begin{array}{c}4 \\
268\end{array}$ & $\begin{array}{l}20.0 \\
45.3\end{array}$ & $\begin{array}{c}7 \\
175\end{array}$ & $\begin{array}{l}35.0 \\
29.6\end{array}$ & $\begin{array}{c}9 \\
149\end{array}$ & $\begin{array}{l}45.0 \\
25.2\end{array}$ & $5.919^{\mathrm{a}}$ & 2 & 0.052 \\
\hline
\end{tabular}

Table 3. The association between demographic characteristics and level of anxiety

* For the mean and $s d$ see the Table 4 


\section{Table 4 (on next page)}

Table 4

Descriptive analysis (frequency, percentage, mean and SD) 
Table 4. Descriptive analysis (frequency, percentage, mean and SD)

\begin{tabular}{|c|c|c|c|c|}
\hline Demographic Profile & $\mathbf{N}$ & $\%$ & Mean & SD \\
\hline \multicolumn{5}{|c|}{ Type of health care facility } \\
\hline Government & 202 & 31.3 & 7.39 & 5.34 \\
\hline Private & 444 & 68.7 & 7.73 & 6.02 \\
\hline \multicolumn{5}{|l|}{ Age* } \\
\hline 20-30 Years Old & 123 & 32.4 & 6.24 & 4.92 \\
\hline 31-40 Years Old & 177 & 46.6 & 7.62 & 5.37 \\
\hline 41-50 Years Old & 63 & 16.6 & 5.98 & 5.18 \\
\hline Above 50 Years Old & 17 & 4.5 & 4.29 & 4.00 \\
\hline \multicolumn{5}{|l|}{ Gender } \\
\hline Male & 167 & 26.0 & 6.79 & 5.61 \\
\hline Female & 475 & 74.0 & 7.96 & 5.86 \\
\hline \multicolumn{5}{|l|}{ Nationality* } \\
\hline Saudi & 189 & 29.6 & 8.33 & 5.54 \\
\hline Non Saudi & 450 & 70.4 & 7.34 & 5.88 \\
\hline \multicolumn{5}{|l|}{ Health specialty* } \\
\hline Physicians & 114 & 17.7 & 7.66 & 5.70 \\
\hline Nurses & 323 & 50.2 & 7.26 & 5.68 \\
\hline Others & 207 & 32.1 & 8.05 & 6.02 \\
\hline \multicolumn{5}{|l|}{ Hospital Department } \\
\hline ER Department & 52 & 8.2 & 7.73 & 5.65 \\
\hline Ward & 134 & 21.1 & 7.21 & 6.05 \\
\hline ICU Department & 243 & 38.3 & 7.75 & 5.53 \\
\hline Others & 206 & 32.4 & 7.72 & 6.01 \\
\hline \multicolumn{5}{|l|}{ Years of experience } \\
\hline 1-5Years & 280 & 44.3 & 7.43 & 5.62 \\
\hline 6-10Years & 177 & 28.0 & 8.68 & 6.16 \\
\hline 11 Years and Above & 175 & 27.7 & 6.78 & 5.59 \\
\hline \multicolumn{5}{|c|}{ Sleeping disorder before covid-19* } \\
\hline Yes & 80 & 13.1 & 8.98 & 5.33 \\
\hline No & 532 & 86.9 & 7.05 & 5.51 \\
\hline \multicolumn{5}{|l|}{ Mental Disorder } \\
\hline Yes & 20 & 3.3 & 11.11 & 6.39 \\
\hline No & 592 & 96.7 & 7.20 & 5.49 \\
\hline
\end{tabular}




\section{Table 5 (on next page)}

Table 5

Model Summary Statistic 
1

2

\begin{tabular}{lcccc}
\hline Model Summary & Chi-Square & df & p value & R2 \\
\hline $\begin{array}{l}\text { Model Fitting Information } \\
\text { Final model }\end{array}$ & 19.292 & 3 & $<0.001$ & \\
Goodness-of-Fit & & & & \\
Pearson & 10.897 & 11 & 0.452 & \\
Deviance & 11.231 & 11 & 0.424 & \\
Pseudo R-Square & & & & 0.031 \\
Cox and Snell & & & & 0.035 \\
Nagelkerke & & & & 0.015 \\
McFadden & & & & \\
Test of Parallel Lines & 5.826 & 3 & 0.120 & \\
General & &
\end{tabular}

Table 5. Model Summary Statistic

3 


\section{Table 6(on next page)}

\section{Table 6}

Summary statistic for ordinal logistic regression estimation 
1

2

3

\begin{tabular}{|c|c|c|c|c|c|c|c|}
\hline \multirow[t]{2}{*}{ Parameter Estimates } & \multirow[t]{2}{*}{ B } & \multirow[t]{2}{*}{ OR } & \multicolumn{2}{|c|}{$95 \% \mathrm{CI}$} & \multirow[t]{2}{*}{ Wald } & \multirow[t]{2}{*}{ df } & \multirow[t]{2}{*}{$p$ Value } \\
\hline & & & Lower & Upper & & & \\
\hline \multicolumn{8}{|l|}{ Threshold } \\
\hline$[$ LEVEL_ANXIETY $=1.00]$ & -0.121 & & & & 1.4 & 1 & 0.245 \\
\hline [LEVEL_ANXIETY $=2.00]$ & 1.221 & & & & 110.7 & 1 & 0.000 \\
\hline Location & & & & & & & \\
\hline $\begin{array}{l}{[\text { Gender }=1] \text { Male }} \\
{[\text { Gender }=2] \text { Female (ref.) }}\end{array}$ & -0.388 & 0.678 & 0.475 & 0.970 & 4.5 & 1 & 0.034 \\
\hline $\begin{array}{l}{[\text { Nationality }=1] \text { Saudi }} \\
{[\text { Nationality }=2] \text { Non Saudi (ref.) }}\end{array}$ & 0.460 & 1.584 & 1.127 & 2.226 & 7.0 & 1 & 0.008 \\
\hline $\begin{array}{l}{[\text { SleepingDisorder }=1] \text { Yes }} \\
{[\text { SleepingDisorder }=2] \text { No (ref.) }}\end{array}$ & 0.555 & 1.742 & 1.119 & 2.713 & 6.0 & 1 & 0.014 \\
\hline
\end{tabular}

Table 6. Summary statistic for ordinal logistic regression estimation

Link function: Logit 
Figure 1

Figure 1. Flow chart 
- Eligible participants identified

- A total of 900 questionnaires were distributed among healthcare providers

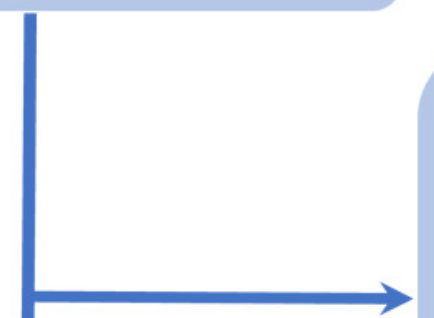

- 22 years old or above,

- Responsible for providing direct patient care in an inpatient or outpatient healthcare setting,

- Spent at least 6 months in the current

- 650 participants completed surveys

- Response rate of $72 \%$ 
Figure 2

Figure 2. Level of anxiety 


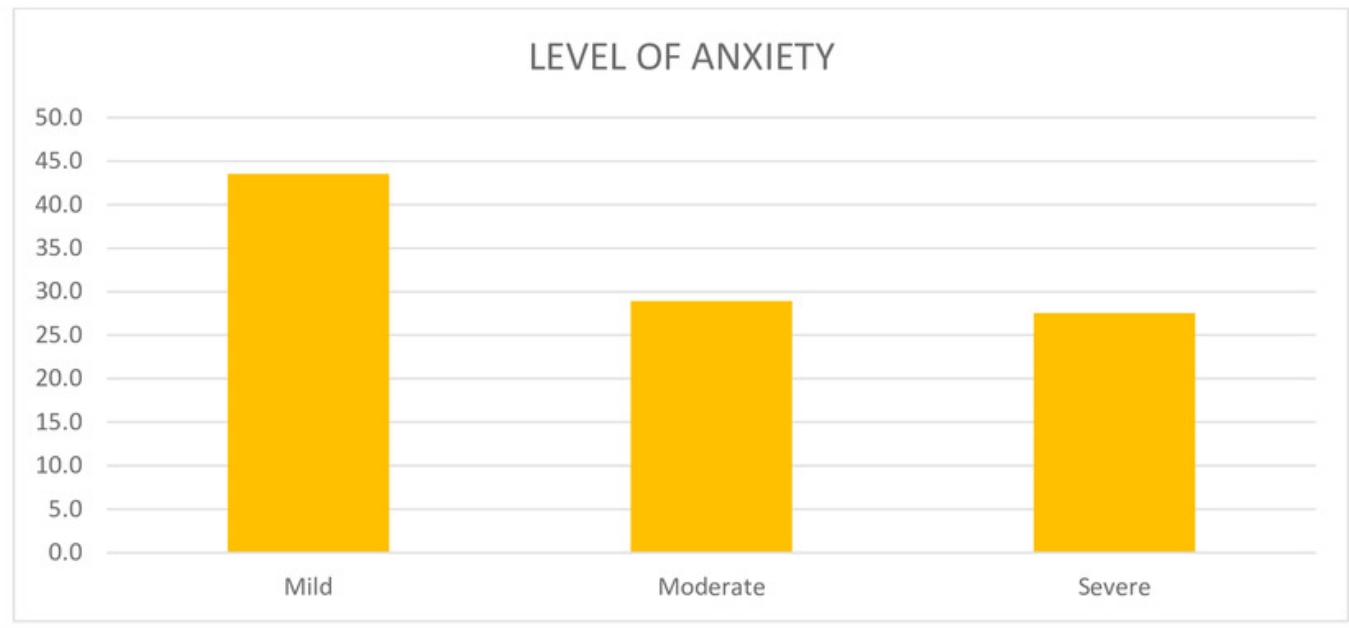

